\title{
O PODER DAS EMPRESAS TRANSNACIONAIS E A PRODUÇÃO DA ELISÃO FISCAL: O CASO DO CONSUMO DA COCA-COLA NO MUNDO CONTEMPORÂNEO
}

\author{
Lucas Dalmora Bonissoni* \\ Isadora K. Lazaretti**
}

\section{RESUMO:}

Este estudo versa sobre o poder das empresas transnacionais e a produção da elisão fiscal, com base no caso da Coca-Cola no mundo contemporâneo. A pesquisa é realizada adotandose o método dedutivo e a técnica de pesquisa bibliográfica. $\mathrm{O}$ objetivo geral busca verificar o poder das empresas transnacionais e como elas podem produzir elisão fiscal. Considerada uma das marcas mais influentes do mundo, a Coca-Cola efetua manobras fiscais, como a elisão fiscal, consistente na redução do pagamento de tributos, procurando se instalar em países em que os regimes fiscais sejam privilegiados, utilizando indevidamente os destinos fiscais em seu próprio benefício.

Palavras-chave: empresas transnacionais; relações de poder; poder econômico; elisão fiscal.

\section{THE POWER OF TRANSNATIONAL COMPANIES AND FISCAL ELISION PRODUCTION: THE CASE OF COCA-COLA CONSUMPTION IN THE CONTEMPORARY WORLD}

\begin{abstract}
:
This study aims with the power of transnational corporations and the production of tax avoidance, based on the case of Coca-Cola in the contemporary world. The research is performed using the deductive method and the technique of bibliographic research. The overall objective is to verify the power of transnational corporations and how they can produce tax avoidance. Considered one of the most influential brands in the world, Coca-Cola performs fiscal maneuvers, such as tax avoidance, consisting in reducing tax payments, seeking to settle in countries where tax regimes are privileged, misusing tax destinations in their own benefit.
\end{abstract}

Keywords: transnational corporations; Power relations; economic power; tax avoidance.

\section{INTRODUÇÃO}

Este estudo versa sobre o poder das empresas transnacionais e a produção da elisão fiscal, com base em uma breve análise do caso da Coca-Cola no mundo contemporâneo.

\footnotetext{
* Mestrando em Direito pela Universidade de Passo Fundo - UPF. Endereço postal: Av. Herculano H. Zanuzzo, 632, Seara - SC. Cep 89770-000. E-mail: lucasdbonissoni@hotmail.com

** Doutoranda em Direito pela Universidade do Oeste de Santa Catarina (UNOESC). Endereço postal: Av. Herculano H. Zanuzzo, 632, Seara - SC. Cep 89770-000. E-mail: isadoralazaretti@hotmail.com
} 
Trata-se de um tema complexo e ao mesmo tempo contemporâneo, porque enfrenta situações e relações de poder que se manifestam atualmente em nossa sociedade - seja no âmbito internacional ou nacional.

O objetivo geral dessa pesquisa consiste em verificar o poder das empresas transnacionais e como elas podem produzir elisão fiscal atualmente, especialmente observando dados que envolvem a Coca-Cola, considerada uma das empresas que está no ranking das mais valiosas marcas do mundo. Especificamente, objetiva-se estudar o poder enquanto categoria conceitual e suas relações na sociedade contemporânea e, por fim, investigar o poder das empresas transnacionais e a produção da elisão fiscal, a partir de breves apontamentos envolvendo a Coca-Cola nesse ramo.

A importância se fundamenta pela contemporaneidade do tema, uma vez que as empresas transnacionais ocupam posição de destaque cada vez mais elevada, já que seu protagonismo ultrapassou limites e fronteiras inimagináveis. O crescimento das empresas transnacionais ao longo dos anos se tornou imensurável, e seu poder de influência inclusive é capaz de interferir nas próprias decisões dos Estados, que, muitas vezes, não possuem efetivo controle sobre as ações dessas empresas em razão do poder econômico do qual são detentoras. O debate, por si só, mostra-se relevante para analisar, dentre as várias esferas do exercício de poder dessas empresas, os traços da elisão fiscal pela Coca-Cola no mundo, e, de forma geral, demonstrar o poder que essas empresas exercem e como isso reflete para a sociedade.

Assim, a investigação do problema de pesquisa tem por base responder a seguinte indagação: Como podem qual o poder das empresas transnacionais para a produção da elisão fiscal no mundo contemporâneo, a partir da análise do caso da Coca-Cola, enquanto uma das mais poderosas marcas mundialmente reconhecidas?

Para alcançar os objetivos propostos e responder à problemática a ser investigada, o presente artigo se divide em dois tópicos estruturantes: o primeiro versa sobre o estudo do poder como categoria conceitual e suas relações na sociedade contemporânea, cuja abordagem é direcionada ao conceito de poder e suas características, a partir de uma explanação dos principais autores que se debruçaram sobre o tema; no segundo, o estudo aborda a análise do poder das empresas transnacionais e a produção da elisão fisscal, abordando a influência que essas empresas exercem no cenário internacional e também nacional, especialmente com a produção da elisão fiscal, utilizando-se como exemplo o caso 
da Coca-Cola a nível global.

Quanto aos procedimentos metodológicos, utilizou-se o método dedutivo, sendo a pesquisa de caráter qualitativo. Como técnica de pesquisa utilizou-se a pesquisa bibliográfica.

\section{O PODER COMO CATEGORIA CONCEITUAL E SUAS RELAÇÕES}

O estudo das relações de poder na sociedade - seja internacional, seja nacional configura um dos elementos essenciais para a compreensão do mundo contemporâneo. Compreender o poder configura uma tarefa complexa e desafia os estudiosos por se tratar de um objeto de conhecimento multidimensional que se encontra em construção e transformação ao longo dos anos (OLSSON, 2007, p. 43).

Como enfatiza Bartolomé Ruiz (2004. p. 09), “o poder é a sombra de nossa prática e a luz de nossas criações”. A definição de poder de Bartolomé Ruiz expressa o quanto o poder configura um importante instrumento para a compreensão das relações entre os homens nos mais diversos aspectos do conhecimento. Ele afirma que o poder "é uma palavra que todo mundo entender, mas que ninguém consegue explicar”, daí decorrendo a complexidade da definição desse conceito.

Igualmente, Morriss (1987. p. 36-37) também afirma ser necessária a conceituação do poder, apesar da fluidez e da dificuldade de identificar seu exercício. Para ele, essa dificuldade está diretamente relacionada com a diversidade de expectativas construídas em torno de sua referência.

Para Olsson, (2007, p.50) a definição do poder exige uma "tentativa de reconstrução dos seus diversos significados desenvolvidos" com ênfase na "conjugação de suas identidades e dessemelhanças como um saber em construção".

O que seria, então, o poder? Como forma de resposta para tal indagação, Bartolomé Ruiz afirma que o poder não está em um lugar definido e não se localiza em uma dimensão específica. Para ele, “o poder não existe como uma coisa, com uma natureza específica, não existe em si nem por si”. Na sua concepção, questionar "o que é o poder" é um erro, porque ele não é, ele atua, na medida em que está presente nas práticas e relações humanas, se articulando como um modo de ser da ação (2004, p. 10).

O conceito de poder desempenha um papel de importância, uma vez que, de um 
lado, integra a base de conceitos que forma o conjunto de teorias e práticas de uma determinada sociedade e, de outro, configura um discurso que reflete e legitima as práticas sociais.

O poder é um conceito que se relaciona com o próprio discurso da política, e "reside num nível muito grande de desarmonia subjacente entre indivíduos e sociedade”. Ele quer dizer que a sociedade, em si, depende primeiramente do fato que "algumas pessoas são sistematicamente dominadas por outras" (GOVERDE et al, 2000, p. 05).

Em verdade, o poder envolve uma série de estudos que torna difícil ou até mesmo intelectualmente impossível a compreensão de todas as concepções em torno desse complexo objeto de estudo. Aliás, a título exemplificativo trazido pelo autor, uma simples pesquisa na base de dados do Instituto Universitário Europeu com a palavra-chave "poder" indica mais de três mil obras no seu acervo apenas nas áreas do Direito, da História e das Ciências Sociais e Políticas (2007, p. 54).

O poder vem sendo estudado por importantes filósofos nas mais diversas épocas, assim como por estudiosos contemporâneos que se debruçaram sobre o tema nos últimos anos. Aristóteles, por exemplo, estudou questões relacionadas ao poder, que podem ser facilmente percebidas nos seus escritos, especialmente quando qualifica o homem como um "animal político", ao atribuir-lhe o poder da fala (ARISTÓTELES, 1993, p. 13).

Maquiavel (1999) analisou o poder a partir de uma perspectiva prática, tendo seu nome associado ao poder político quando se posiciona sobre a realidade dos Estados e seus governantes, e os mecanismos e estratégias para adquirir e manter esse poder, que é vislumbrada na sua obra mais conhecida "O Príncipe".

Hobbes também se posicionou sobre o poder ao associá-lo com a natureza do homem, mencionando que "por tendência geral de todo o ser humano, o desejo perpétuo e incessante de poder depois de poder, o qual cessa apenas com a morte" (1988, p. 64). Assim como Maquiavel, Locke também se interessou pelo poder político, e afirmava que por poder político poderia se considerar "um direito de fazer leis, com pena de morte, e consequentemente todo o tipo de penalidade menos severa" (2005, p. 64), expressando, assim, a legitimidade do Estado e a sujeição do indivíduo ao ente soberano.

O termo “poder”, segundo a concepção de Bartolomé Ruiz “é uma palavra pela qual designamos um conjunto de significações polimorfas que podem adquirir diversos sentidos segundo as circunstâncias e o modo como se realizam as práticas humanas". Para ele, o 
poder é um símbolo, na medida em que por meio dessa palavra é possível conotar um conjunto de sentidos, sem perceber uma conotação única ou uma definição exata (2004, p.10).

Bourdieu também estuda o poder a partir do simbolismo. Ele analisa o poder simbólico, conceituado como "aquele poder invisível que pode ser exercido somente com a cumplicidade daqueles que não querem saber que eles são sujeitos a ele ou mesmo que ele s próprios exercem ele" (1991, p.164).

O poder configura a noção de submissão de alguns à vontade alheia, de modo que sua ocorrência é inevitável no período moderno, uma vez que nada em nossa sociedade é realizado sem ele. Ainda, o poder pode ser considerado socialmente malévolo ao mesmo tempo que é imprescindível nas relações humanas e sociais do nosso mundo contemporâneo (GALBRAITH, 1986, p.13).

Foucault acredita que o poder não se manifesta como uma propriedade, ou seja, algo apropriável que o indivíduo possui. Para ele (2014, p.18), o poder se manifesta a partir de relações ou práticas de poder. Essa premissa demonstra e configura a percepção de que o poder funciona como uma "máquina social" que se dissemina pelas estruturas sociais sem estar presente em um local específico. O poder pode ser definido ainda a partir do conceito de autoridade, submissão, coerção, influência, manipulação e força (BACHRACH, 1970, p. 17).

O conceito de poder é visto ainda como "disposicional", na medida em que se manifesta como uma "capacidade" ou uma "habilidade", porque às vezes, pode não ser exercido, de forma que não é sempre que seu exercício se dá. Esse pode ser considerado como a "habilidade dos agentes de produzir efeitos significativos, especialmente por levarem adiante seus próprios interesses e/ou afetarem os interesses de outros, tanto positivamente quanto negativamente" (LUKES, 1986, p. 65).

Max Weber (1999, p. 531), define poder como a "possibilidade dentro de um relacionamento social, de realizar a vontade de alguém mesmo contra resistência, independentemente da base na qual essa possibilidade se funda". Ele ainda relata outras passagens envolvendo o poder, ao mencionar que o poder pode ser considerado como uma possibilidade de um indivíduo ou um grupo fazer prevalecer sua vontade, ainda que hajam outras envolvidos que ofereçam resistência. Para Weber, o poder pode ser "a possibilidade de impor a vontade de alguém sobre a conduta de outros” (1999, p. 532). 
Um indivíduo pode ser detentor de poder sobre outro ou outros, de modo que esse poder se torna "efetivamente relacional" ainda que não se trate de um relacionamento. Ou, em outro vértice, alguém "pode ter poder para fazer ou realizar alguma coisa por ele próprio, e esse poder não é relacional [...] ele pode envolver outras pessoas se o que ele tem poder para fazer é uma ação social ou política” (PITKIN, 1972, p. 177).

Segundo Dowding (1991, p. 05-06), existem duas divisões principais que envolvem o estudo da teoria do poder: a primeira, expressa-se pela manutenção do poder por indivíduos ou estruturas, enquanto que a segunda, relaciona-se à definições causais e disposicionais. Ele considera que o poder é uma "propriedade disposicional de um objeto", considerada uma disponibilidade ou capacidade, porque “[...] encontra-seem uma faculdade de ser exercido ou não".

Dyrberg (1997, p. 07) analisou a origem do poder com base em duas concepções: a concepção derivativa e a concepção não-derivativa. Na concepção derivativa, o poder é tido como um resultado ou numa estrutura do qual o agente está inserido. Na política, por exemplo, é a própria estrutura do poder político que perpassa o poder aos indivíduos. Já na concepção não-derivativa, Dyrberg enfatiza que o poder configura "uma relação ou processo irredutível; irredutível no sentido de que ele não pode ser derivado de nada acima, além ou pré-existente às próprias relações que constituem esse processo".

Bartolomé Ruiz considera que o poder está inserido em toda relação e prática humana, e atua em várias áreas, como na solidariedade, no amor e na gratuidade, pois tende a ajudar o próximo na busca de seu crescimento. Ele direciona sua concepção especialmente ao simbolismo do poder, e menciona que esse simbolismo "implica a pessoa na sua prática de tal modo que, ao pretender explicar o que seja esse poder, sempre se encontra com seu próprio rosto". Para Bartolomé Ruiz (2004, p. 12-13) “o poder afeta diretamente os modos de subjetivação, determinando o que somos”.

Em verdade, ao longo da evolução dos debates envolvendo o poder, esse objeto passou a ser estudado por diversas áreas do conhecimento. Na filosofia, por exemplo, o poder se tornou importante para delimitar hierarquias de valoração de saberes da própria possibilidade de conhecimento do homem. Na sociologia, o debate do poder se relaciona com os valores que estão inseridos na sociedade e nas relações do homem com esses valores. $\mathrm{Na}$ economia, o poder é estudo a partir de sua importância no mercado e nas relações econômicas. Na psicologia, o estudo do poder se direciona para a constituição do homem, 
seus desejos e suas expectativas. Por fim, no campo jurídico, o poder está diretamente ligado aos instrumentos de regulação jurídica e controle social, enquanto que, na política, o poder é discutido com base nos interesses coletivos de determinado grupo (OLSSON, 2014, p. 136).

Veja-se, portanto, que o poder se dissemina pela estrutura social e não existe como uma coisa apropriável, como bem pensava Foucault. Mas, como Bartolomé Ruiz (2004) o poder não é "algo", ele "atua" e faz parte de todas as práticas e relações humanas, inserido constantemente nas relações sociais, políticas e jurídicas de forma articulada, de natureza multidimensional.

Assim, feita a análise do poder enquanto categoria conceitual e suas relações, passase a analisar o poder das empresas transnacionais e a produção da elisão fiscal em relação ao consumo da Coca-Cola no Mundo.

\section{O PODER DAS EMPRESAS TRANSNACIONAIS E A PRODUÇÃO DA ELISÃO FISCAL: O CASO DO CONSUMO DA COCA-COLA NO MUNDO}

As empresas transnacionais são consideradas importantes atores da sociedade nacional e são igualmente conhecidas como empresas multinacionais. Dentre sua terminologia, Fernandes (1998, p. 65-66) apresenta as seguintes diferenciações: “empresa internacional", considerada aquela que reagrupa sua atuação e suas operações internacionais, encarando estratégias no mercado internacional e nos investimentos diretos; "empresa multinacional" que atua e expande seus recursos para além das fronteiras nacionais, mas considera suas operações no exterior tão importantes como as que ocorrem no nível nacional; e, por fim, "empresas transnacionais" coordenada por pessoas de diferentes nacionalidades e sua atuação escapa totalmente do domínio nacional, se expandindo, assim como as multinacionais, para além das fronteiras territoriais delimitadas em determinado Estado.

Oliveira (2013, p. 235) considera que existe uma tendência geral de autores americanos de utilizarem o termo "empresa transnacional" para definir "aquelas empresas que, originárias e com sede em países industrializados, detêm filiais e boa parte de seus negócios em outros países”. Em contrapartida, considerada a autora, os autores europeus utilizam a expressão "empresa transnacional" para designar aquelas "empresas ou sociedades que atuam em vários países, segundo diversos modos, mas sempre com a mesma 
lógica comum de atuação".

As empresas transnacionais são aquelas que "correspondem a pessoas de nacionalidades diferentes e que são por elas dirigidas"(CHRISTENSEN, 1976, p. 28). A expressão "empresas transnacionais" acoberta um conjunto de situações e fatores, especialmente a fuga dos controles internacionais. Elas se tornaram empresas juridicamente desnacionalizadas, porque, na medida em que instalam suas unidades em vários países de todos os continentes, os montantes de seus ativos financeiros e a lucratividade esperada como seus resultados estão descentralizados no exterior.

Para Bedin (2001, p. 315), as empresas transnacionais realizam a unidade do mercado mundializado, movidas pela política do "máximo lucro ao menor custo". Elas transformam as estruturas econômicas, sociais e até mesmo políticas, porque possuem a capacidade de influenciar inclusive os próprios Estados por conta de seu poder econômico.

Importa salientar, como considera Seitenfus (2000, p. 27), que as empresas transnacionais "possuem uma matriz num determinado Estado e atividades de produção ou serviços através de filiais localizadas em outros Estados”. É por conta disso que não se comparam as empresas nacionais - seja por seu escopo de atuação, mas especialmente por sua principal característica que é seu capital.

Nesse sentido, Olsson (2007, p. 324) considera que "nos últimos séculos, as grandes empresas eram essencialmente de base nacional", de modo que "seu capital era entendido como parte do poder econômico do próprio Estado", sendo que esse poder era considerado "como a maior unidade de grandeza conhecida em termos de poder econômico". Logo, como enfatiza Olsson, “o poder em sentido amplo (inclusive o econômico) era do 'Estado' e não da empresa".

Contudo, com o surgimento das empresas transnacionais e, consequentemente, com a transnacionalização das atividades econômicas, esse poder não é mais pertencente ao Estado, e sim, da própria empresa, por conta do volume de capital que possuem (OLSSON, 2007, p. 324).

As atividades das corporações transnacionais refletem diretamente na sociedade, principalmente por proporcionar empregos para os cidadãos, e, até mesmo, para o consumo de seus produtos diante da produção em alta escala. Sob essa realidade, as corporações são consideradas como atores internacionais que melhor se conectam com a sociedade, principalmente por conta dos seus ideais de maximização do lucro e minimização dos 
custos, porque diretamente geram desigualdades econômicas, sociopolíticas e jurídicas, devido às consequências ocasionadas pelo fenômeno globalizante (KAWAMURA, 2014, p. 55-57).

Como a fraude global tem mostrado desde 2008, os Estados entregaram bilhões de dólares às principais corporações transnacionais, diretamente envolvidas na geração da crise econômica global. Por exemplo, para o ano 2000 a onça de ouro custou US\$ 270 e o barril de petróleo foi de US\$60, até o início de 2012 o ouro está em US\$ 1.700 e o petróleo em torno de US\$108, com projeções para o aumento contínuo. Os enormes lucros do capital global para a exploração de matérias-primas no Terceiro Mundo têm como principal componente a especulação rentista (QUIJANO, 2014, p. 233-234).

Essas empresas são tão poderosas que seu poder econômico supera inclusive o dos Estados, na medida em que o faturamento anual das transnacionais pode facilmente superar produto interno bruno de vários países. Por exemplo, a comparação entre o faturamento anual dessas empresas com o produto interno produto de alguns estados feita por Olsson, torna bastante clara tal afirmativa e revela o poder extraordinário desses atores. Em 1992, “o faturamento da 'General Motors' foi de cerca de 130 bilhões de dólares, o da 'Exxon' foi de mais de 120 bilhões e o da 'Ford' foi de cerca de 100 bilhões”. Enquanto isso, no mesmo ano, “o produto interno bruno de Estados como a Arábia Saudita e a Indonésia foi de 105 bilhões de dólares, e o da Noruega de 100 bilhões de dólares”. Assim, com base nessa comparação, é possível verificar que a "General Motors" consegue vender, em menos de dois meses, o que o Egito leva um ano inteiro para produzir (OLSSON, 2007, p. 325).

Warat (2010, p. 21) utiliza o termo "máfia S.A" para se referir às empresas transnacionais, e na sua concepção, na medida em que atuam e crescem, elas estão conseguindo cada vez mais efeitos devastadores, e constituem uma "ameaça maior que a nuclear. Para ele, "a máfia S.A está conseguindo destruir tudo, incluindo a fonte de sua própria riqueza".

Com a intenção de "criar falsos lucros" para os Entes Federativos, a partir do século XXI, passou-se a iniciar uma inclusão das corporações nas áreas públicas (DOWBOR, 2016).

Nesse sentido, é indispensável à anuência do ente local para que as atividades comerciais iniciem seus serviços em determinado território. Por outro lado, uma das formas de expressão do poder transnacional ocorre quando as corporações conseguem instalar-se 
nos países independente de autorização, ou seja, "várias companhias globais como a Exxon, Toyota, Mitsubishi, Nestlé, Siemens, Hyundai, BASF, Monsanto, têm o poder de modelar o mundo à sua vontade" (SALLES, 2017, p. 96-97).

Portanto, nem sempre o início das atividades industriais de uma corporação transnacional decorre pelo meio político ou necessidade social do território, e sim, devida sua capacidade de produzir lucros e ser protagonista em âmbito nacional e internacional, com o objetivo de conquistar novas transações.

As corporações transnacional extraem dos Entes Federados proveitos indiretos devido à falta de regulamentação de legislação nacional, sobretudo no que tange as normas relacionadas ao direito tributário, "na medida em que se torna apta a transitar da forma mais proveitosa nas lacunas dos diversos sistemas jurídicos estatais, perfazendo uma elisão combinada dos sistemas jurídicos" (OLSSON, 2003, p. 180-181).

Assim, devido a posição econômica superior das corporações, elas desconhecem os limites estatais e conseguem instalar-se em regiões que tendem a oferecer regimes tributários mais brandos (SCHNEIDER, 2014, p. 196).

Logo, percebe-se que essa prática se trata de um aproveitamento combinado pela fragilidade dos sistemas jurídicos nacionais em termos de aplicação do direito interno, uma vez que alguns Estados estabelecem como critério o local do registro, e outros o local da matriz para esse efeito (OLSSON, 2007, p. 321-322).

Elisão significa de elidir, eliminar, suprir, ou seja, reduzir o pagamento de tributos através de planejamento, e sua prática é propiciada pela existência de paraísos fiscais com regimes privilegiados que passaram a demandar a cooperação entre as corporações para evitar a utilização indevida desses destinos fiscais (SCHNEIDER, 2014, p. 196). No entender de Fabretti (2005, p.153) “a elisão fiscal é legítima e lícita, pois é alcançada por escolha feita de acordo com o ordenamento jurídico, adotando-se a alternativa legal menos onerosa ou utilizando-se de lacunas da lei”.

A título exemplificativo, tal conduta ocorre no Brasil, como noticiado por diversos jornais e revistas renomadas no caso da "Coca-Cola" que hoje ameaça deixar o país caso não sejam mantidos seus benefícios tributários, por se tratar de altas cifras e ser considerada uma das marcas mais influentes do mundo. Por outro lado, aparece reiteradas denúncias de manobras tributárias bilionárias e prejudiciais aos cofres públicos. "A Coca-Cola recebe a maior parte dos dois bilhões de reais anuais devolvidos de IPI a quem compra concentrados 
de refrigerantes, chás e sucos na Zona Franca" (CARTA CAPITAL, 2018), segundo cálculos da Receita Federal, isso se somam 200 milhões de PIS-Cofins e 1 bilhão de Imposto sobre Circulação de Mercadorias e Serviços, que a União, Estados e Municípios deixam de arrecadar durante o ano.

Além disso, a Coca-Cola restituiu apenas 20,4\% de obrigações tributárias sobre os seus lucros, ou seja, quase $15 \%$ a menos do que deveria recolher. Segundo pesquisa sobre seus representantes internos "enquanto os legisladores dos Estados Unidos procuram reformar o código tributário das empresas, esse relatório mostra que o foco de qualquer revisão deve ser o fechamento de brechas, em vez de reduzir as alíquotas” (JOIO E TRIGO, 2018) .

Dessa forma, observa-se que muitos países são reféns das corporações transnacionais, por tratar de uma falsa concepção de riqueza, caso o Estado regule as normas tributárias, poderá ser ameaçado a perder as empresas de seu país, e se continuar mantendo a legislação branda perderá bilhões de reais anualmente, que poderiam ser investidos em educação e saúde, gerando um desiquilíbrio na administração.

Por outro lado, a Coca-Cola além de gerar empregos aos Estados, distribuí seu produto em todo o território nacional, e, além disso trata-se da bebida mais consumida no mundo, com aproximadamente 1,8 bilhões de porção de bebidas vendidas por dia. Assim, perder uma empresa com tamanha visibilidade torna o Estado refém da corporação, por estar inserida na sociedade brasileira e mundial há séculos.

Nesse sentido, completa Lipovestsky (2011, p. 31) que "chegamos ao momento em que a comercialização dos modos de vida não mais encontra resistência estruturais, culturais e nem ideológicas; e em que as esferas da vida social e individual se reorganizam em função da lógica do consumo".

Diante desse cenário, o consumo da Coca-Cola está conectado com a sociedade e com todos os meios de marketing possível, onde se inseriu hábitos ao consumidor por meio de uma "apoteose" publicitária (BAUMAN, 2008, p. 70). Com a vinculação dos aspectos de divulgação comercial, seja por anúncios de televisão, internet ou rádio que "se manifesta de diversos meios, implícitos e explícitos, tornando a vida do cidadão manipulada para o consumo" (PEREIRA, 2009, p. 13).

Sucessivamente, as pessoas acabam consumindo para satisfazer suas futilidades, apenas ao lembrar-se do slogan vermelho marcado pelas campanhas publicitárias, que tem 
um grande enfoque em pessoas felizes rodeadas de amigos consumindo essa bebida.

Como resultado, o sujeito acaba tornando-se a própria mercadoria desejável diante de sua comunidade, e da produção de bens de consumo ser agora um fenômeno cultural: compra-se o produto tanto por sua imagem quanto por sua identidade imediata (JAMESON, 1996, p. 138). Portanto, o homem não está mais preocupado em sobreviver, mas, sim, "consumir para poder viver ou se o homem vive para poder consumir" (BAUMAN, 1999, p.88).

É importante destacar que existe grande relevância do poder da marca que cada corporação tem nos Estados, devido seu alto renome pode gozar de excelente reputação e prestígio para todos os consumidores (PORTO, 2018). No caso da Coca-Cola, esse poder é evidente, porque não se trata apenas do consumo em si da bebida, mas de todos os outros produtos que são objeto de comercialização pela Coca-Cola e que são altamente consumidos por conta da marca.

Verifica-se, por conseguinte, que o poder das empresas transnacionais, assim como a Coca-Cola, na atualidade, ocupa posição de destaque em relação aos demais protagonistas que se manifestam no cenário internacional e nacional, inclusive, superior aos próprios Estados, uma vez que estendem-se e se deslocam ao mesmo tempo. Além disso, desconhecem limites, territórios e fronteiras, e limitam e fragilizam o poder dos Estados, porque competem com eles de forma direta (OLIVEIRA, 2016, p. 194).

A Coca-Cola se tornou tão poderosa economicamente no mundo contemporâneo que escapa diretamente da ótica normativa nacional, uma vez que suas operações não se encontram ao alcance das políticas nacionais dos países nos quais estão hospedadas. É ela quem determina suas próprias regras, seus próprios regimes e seus princípios norteadores, independente do Estado que esteja instalada.

Não se pode dizer, contudo, que a Coca-Cola está livre de qualquer controle e fiscalização, mas é certo que essa poderosa transnacional procura instalar suas grandes unidades de produção nos Estados em que as normas trabalhistas, ambientais e fiscais são mais brandas, isto é, naqueles que possam oferecer as maiores e melhores condições de lucros fáceis totalmente garantidos, utilizando todos os recursos disponíveis das áreas selecionadas. Importa frisar ainda que, caso não sejam alcançados os resultados esperados, ela pode simplesmente fechar as portas e se deslocar para outro local, desestruturando totalmente o espaço social no qual estava inserida. 
Por fim, por meio do alcance dos objetivos propostos neste estudo, foi possível concluir que as empresas transnacionais exercem um destacado poder na sociedade contemporânea, que pode, inclusive, ser superior ao poder dos próprios Estados, especialmente se analisado do ponto de vista econômico. Esse poder se manifesta pela própria atuação das empresas transnacionais na sociedade globalizada, que, na busca da maximização do lucro a qualquer custo, não se importa com os reflexos negativos que suas ações são causadoras, seja à sociedade em geral, à economia, ao desenvolvimento, ao meio ambiente, e à saúde global.

\section{CONCLUSÃO}

A partir da realização do presente estudo, foi possível verificar que o poder exerce grande importância na sociedade e configura um elemento essencial para a compreensão do mundo contemporâneo. Verificou-se, ainda, que o poder se manifesta das mais diversas formas, e, especificamente, como escolha do objeto de estudo, manifesta-se por intermédio das empresas transnacionais.

As empresas transnacionais constituem-se enquanto importantes atores da sociedade internacional e nacional. Configuram-se por sua dimensão e grandeza, por se instalarem em diversos países e são também conhecidas globalmente como empresas multinacionais. Sua principal característica está relacionada com sua atuação no mercado mundial, por serem movidas sempre pela política de alcançar a máxima lucratividade ao menor custo possível.

Diante dessas premissas, o estudo verificou a influência e o poder que as empresas transnacionais exercem na sociedade, especificamente, o caso que envolve a Coca-Cola no mundo e a produção da elisão fiscal. A prática da elisão fiscal configura um fenômeno que consiste em reduzir o pagamento de tributos através de planejamento. Contudo, as transnacionais utilizam dessa prática na busca dos chamados "paraísos fiscais", isto é, procuram se instalar em países em que os regimes fiscais sejam privilegiados, utilizando indevidamente os destinos fiscais em seu próprio benefício.

Além da elisão fiscal, o poder das transnacionais se verifica pela prática da elisão combinada dos sistemas jurídicos, uma vez que as empresas transnacionais procuram benefícios nos países cuja legislação ambiental, trabalhista e ainda fiscal. A título exemplificativo, no Brasil, o caso da Coca-Cola efetua manobras fiscais recolhendo $15 \%$ a 
menos de suas obrigações tributárias do que deveria recolher. Inclusive, hoje a Coca-Cola ameaça deixar o país caso não sejam mantidos seus benefícios tributários.

Considerada uma das marcas mais influentes do mundo, a Coca-Cola hoje é considerada uma das mais poderosas empresas, seja em termos de marca, marketing e, principalmente, em termos econômicos. Suas operações escapam as políticas nacionais dos países do qual está instalada, porque é ela quem determina suas próprias regras e seus próprios regimes, influenciando as decisões dos próprios Estados.

O poder das empresas transnacionais atingiu níveis inimagináveis, proporcionado pela globalização e esse fenômeno configura um caminho sem volta porque se torna difícil pensar como o mundo ainda poderá e irá se transformar. Por fim, como considerou Warat (p. 21) vivemos hoje um "tempo do medo, de voracidade e de cinismo", assombrado pela capacidade do dinheiro S.A (isto é, das empresas transnacionais" para ocultar a ordem internacional que predica (prega?) a justiça depende da injustiça”.

\section{REFERÊNCIAS}

ARISTÓTELES. The politics and the constitution of Athens. Edited by Stephen Everson. Revised student edition. Cambridge: Cambridge University Press, 1996.

BACHRACH, Peter; BARATZ, Morton S. Power and poverty: theory and practice. New York: Oxford University Press, 1970.

BARTOLOMÉ RUIZ, Castor. Os labirintos do poder: o poder (do) simbólico e os modos de subjetivação. Porto Alegre: Escritos Editora, 2004.

BAUMAN, Zygmunt. Vida para consumo: a transformação das pessoas em mercadorias. Rio de Janeiro: Editora Zahar, 2008.

Globalização: as consequências humanas. Rio de Janeiro: Editora Zahar, 1999.

BEDIN, Gilmar Antônio. A sociedade internacional e o século XXI: em busca da construção de uma ordem judicial justa e solidária. Ijuí: Ed. Unijuí, 2001.

BOURDIEU, Pierre. Language and symbolic power. Edited and introduced by John B. Thompson. Translated by Gino Raymond and Matthew Adamson. Oxford: Polity Press, 1991.

CARTA CAPITAL. Investigação da receita rastreia fraude fiscal da Coca-Cola. Disponível em: <https://www.cartacapital.com.br/o-joio-e-o-trigo/investigacao-dareceita-rastreia-fraude-fiscal-da-coca-cola/> . Acesso em: 29 dez.2018. 
CHRISTENSEN, Roberto. Empresa multinacional y Estado-nación: tortuosa convivência. 2 ed. Buenos Aires: Depalma, 1976.

DOWBOR, Ladislau. A captura do poder pelo sistema corporativo. Disponível em: <https://dowbor.org/2016/06/a-captura-do-poder-pelo-sistema- corporativo.html/>. Acesso em 29 dez. 2018.

DOWDING, Keith M. Rational choice and political power. Brookfield: Edward Elgar Publishing, 1991.

DYRBERG, Torben Bech. The circular structure of power: politics, identity, community. London: Verso, 1997.

FABRETTI, Láudio Camargo. Código tributário nacional comentado. 5 ed. São Paulo: Atlas, 2005

FERNANDES, Antonio José. Relações internacionais contemporâneas do mundo da Europa a Europa do mundo. Itajaí: Univali, 1998.

FOLHA DE SÃO PAULO. Coca-Cola ameaça deixar o Brasil se não recuperar subsídio na Zona Franca. Disponível em:

<https://www1.folha.uol.com.br/mercado/2018/08/coca-cola-ameaca-deixar-brasil-se- naorecuperar-subsidio-na-zona-franca.shtml>. Acesso em: 29 dez.2018.

FOUCAULT, Michel. Microfísica do poder. 28 ed. Rio de Janeiro: Paz e Terra, 2014.

GALBRAITH, John Kenneth. Anatomia do poder. 2 ed. São Paulo: Pioneira, 1986.

GOVERDE, Henri et al. (Eds.). Power in contemporary politics: theories, practives, globalizations. London: Sage, 2000.

HOBBES, Thomas. Leviatã ou a matéria, forma e poder de um Estado eclesiástico e civil. v. I e II. Tradução João Paulo Monteiro e Maria Beatriz Nizza da Silva. 4 ed. São Paulo: Nova Cultural, 1988.

JAMESON, Frederic. Pós-modernismo: a lógica cultural do capitalismo tardio. São Paulo: Ática, 1996.

KAWAMURA, Karlo Koiti. Arena das empresas transnacionais e o desafio de regulamentação: limite dos regimes internacionais. Ijuí. Unijui, 2014.

LIPOVETSKY, Gilles. Os tempos hipermodernos. 4 ed. São Paulo: Editora Barcarolla, 2011. 
LOCKE, John. Dois tratados sobre o governo. Ed. Peter Laslett. São Paulo: Martins Fontes, 2005.

LUKES, Steven. 2en ed. New York: New York University, 1986.

MAQUIAVEL, Nicolau. O príncipe. Tradução Olívia Bauduh. São Paulo: Nova Cultural, 1999.

MORRISS, Peter. Power: a philosophical analysis. Manchester: Manchester University, 1987.

O JOIO E O TRIGO. Não basta ganhar uma vez: o esquema tributário da Coca é internacional. Disponível em: <https://outraspalavras.net/ojoioeotrigo/2018/08/naobasta-ganhar-uma-vez-coca-cola/> . Acesso em: 29 dez.2018.

OLIVEIRA, Odete Maria de. Relações internacionais: estudos de introdução. 2ed. Curitiba: Juruá, 2013.

; GIACHIN, Isadora e Sá. Atores não estatais e a transnacionalidade: o protagonismo das empresas transnacionais em rede. In: OLIVEIRA, Odete Maria de (Org.). Relações internacionais, direito e poder: atores não estatais na era da rede global. Ijuí: Ed. Unijuí, 2016. v. III. p. 183-230.

OLSSON, Giovanni. Relações internacionais e seus atores na era da globalização. Curitiba: Juruá, 2003.

Poder político e sociedade internacional contemporânea: governança global com e sem governo e seus desafios e possibilidades. Ijuí: Unijuí, 2007.

O poder político no espaço global: o protagonismo dos atores estatais e não estatais. In: OLIVEIRA, Odete Maria de (Org.). Relações internacionais, direito e poder: cenários e protagonismos dos atores não estatais. Ijuí: Ed. Unijuí, 2014. v. I. p. 133-178.

PEREIRA, Agostinho Oli Koppe; PEREIRA, Henrique Mioranza Koppe; PEREIRA, Mariana Mioranza Koppe. Hiperconsumo e ética ambiental. In: PEREIRA, Agostinho Oli Koppe; HORN, Luiz Fernando Del Rio (Orgs.). Relações de consumo: meio ambiente. Caxias do Sul, RS: Educs, 2009.

PITKIN, Hanna Fenichel. Wittgenstein and justice: on the significance of Ludwig Wittgenstein for social and political thought. Berkeley: University of California Press, 1972.

PORTO, Patrícia Carvalho da Rocha. A marca de alto renome e a marca notoriamente conhecida. Disponível em:<http://www.nbb.com.br/pub/propriedade20.pdf>. Acesso em: 29.dez.2018.

QUIJANO, Aníbal. Des/colonialidad y bien vivir: un nuevo debate em América Latina. Primeira edición, dez. 2014. Cátedra América Latina y La Colonialidad del 
Poder. Universidad Ricardo Palma.

SALLES, Eduardo Baldissera Carvalho. A sociedade global e os atores não estatais: o poder das corporações transnacionais. 2017. 1 CD-ROM Dissertação (Mestrado em Direito) - Universidade Comunitária da Região de Chapecó, 2017. Disponível em:

<http://fleming.unochapeco.edu.br:8080/pergamumweb/vinculos/0000eb/0000ebe1.p df $>$. Acesso em: $10 \mathrm{dez} 2018$.

SCHNEIDER, Andressa C. Integração regional e direito tributário internacional. Campinas: Millenium, 2014.

SEITENFUS, Ricardo Antonio da Silva. Manual das organizações internacionais. 2 ed. rev. Amp. Porto Alegre: Livraria do Advogado, 2000.

WARAT, Luis Alberto. A rua grita Dionísio! Direitos humanos da alteridade, surrealismo e cartografia. Trad. Vívian Alves de Assis, Júlio Cesar Marcellino Jr. e Alexandre Morais da Rosa. Editora Lumem Juris. Rio de Janeiro. 2010.

WEBER, Max. Economia e sociedade: fundamentos da sociologia compreensiva. Tradução Regis Barbosa e Karen Elsabe Barbosa; Revisão técnica de Gabriel Cohn. Brasília: Editora Universidade de Brasília, 1999. 